University of Nebraska - Lincoln

DigitalCommons@University of Nebraska - Lincoln

Sociology Department, Faculty Publications

Sociology, Department of

$12-1976$

\title{
Origins of Tolerance: Findings from a Replication of Stouffer's Communism, Conformity, and Civil Liberties
}

\author{
J. Allen Williams Jr. \\ University of Nebraska-Lincoln, jwilliams2@unl.edu \\ Clyde Z. Nunn \\ Center for Policy Research \\ Louis St. Peter \\ lowa State University
}

Follow this and additional works at: https://digitalcommons.unl.edu/sociologyfacpub

Part of the Sociology Commons

Williams, J. Allen Jr.; Nunn, Clyde Z.; and St. Peter, Louis, "Origins of Tolerance: Findings from a Replication of Stouffer's Communism, Conformity, and Civil Liberties" (1976). Sociology Department, Faculty Publications. 123.

https://digitalcommons.unl.edu/sociologyfacpub/123

This Article is brought to you for free and open access by the Sociology, Department of at DigitalCommons@University of Nebraska - Lincoln. It has been accepted for inclusion in Sociology Department, Faculty Publications by an authorized administrator of DigitalCommons@University of Nebraska - Lincoln. 


\title{
Origins of Tolerance: Findings from a Replication of Stouffer's Communism, Conformity, and Civil Liberties*
}

\author{
J. A L LE N W I L L I A M S, J R., University of Nebraska-Lincoln \\ CL Y DE Z. N U N N, Center for Policy Research \\ L O U I S S T. PE T E R, Iowa State University
}

\begin{abstract}
This report presents findings from a nationwide replication of Stouffer's classic study of attitudes toward civil liberties. Central to Stouffer's interpretation of the origins of tolerance is his idea that exposure to social and cultural diversity encourages an appreciation of the importance of civil liberties for democracy. Trends in the 1950s suggested that Americans would increasingly be exposed to diversity with the result that the population would become more tolerant in the future. These propositions were examined using education, city size, region, exposure to mass media news, gender, and occupation as indices of exposure to diversity. With the exceptions of mass media exposure and employment for women, all of these variables were found to be significantly associated with tolerance. And, as Stouffer expected, tolerance has increased greatly over the past two decades.
\end{abstract}

A recent nationwide replication of Stouffer's (1955) classic study of attitudes toward civil liberties in the United States allows us to examine a set of propositions central to his explanation of the origins of tolerance. As part of his more comprehensive social-psychological framework, Stouffer hypothesized that exposure to social and cultural diversity contributes to an understanding of the importance of protecting civil liberties for the maintenance of a democratic society. Processes such as education, urbanization, geographic mobility, exposure to mass media, and change in occupational structure bring people into contact with values, beliefs, life styles, and the like, different from their own. Hence, these processes promote tolerance. Furthermore, given a continuation of social and demographic trends exposing an ever larger proportion of the population to this diversity, the nation should become more tolerant in the future.

*The research was supported by a National Science Foundation Grant GS-36754X. The data for the 1973 replication were collected by Response Analysis. The 1954 data were made available through the InterUniversity Consortium for Political Research. Clyde Z. Nunn is the principal investigator and Harry J. Crockett, Jr. and J. Allen Williams, Jr. are co-investigators of the larger study on which this paper is based. This paper is concerned only with examining one part of Stouffer's general discussion of tolerance. A more complete report will appear in a monograph now being completed. The authors would like to express their appreciation to Harry J. Crockett, Jr., who has contributed significantly to the theoretical and methodological development of the larger study from its inception to the present and who has made valuable suggestions on this paper. We also would like to thank J. Miller McPherson, David R. Johnson, Nicholas Babchuk, and Hugh P. Whitt for their useful comments on earlier versions of the paper. Of course the analysis and interpretation of the data in this paper are the sole responsibility of the authors. 
This paper will examine these propositions by: (1) reanalyzing Stouffer's data through an appropriate form of multiple regression analysis; (2) analyzing data from the replication using the same variables; and (3) comparing the findings from the two studies to see if there has been an increase in the level of tolerance.

\section{SOCIOCULTURAL HETEROGENEITY AND TOLERANCE}

Linking tolerance to the degree of social and cultural diversity in the society has an old and venerable history. Stouffer's departure from previous theories lies primarily in his notion that tolerance arises not simply out of a need to tolerate others because of the interdependence of the division of labor (cf. Durkheim) or out of selfprotection from too much contrast (cf. Simmel; Wirth), but through recognizing that a free society cannot exist unless one is willing to accept the rights of others to think and behave differently. At first, individuals exposed to sociocultural heterogeneity learn that difference per se is not necessarily harmful and that people who act differently are not always dangerous. ${ }^{1}$ This is only a first step, however, because a tolerant person must be willing to accept nonconformity, within the law at least, even if it appears to be dangerous. This lesson begins to be learned when one discovers that his or her own freedom may depend on a willingness to grant the same rights to others. This, in turn, leads to the further recognition that the protection of civil liberties is necessary for the maintenance of a free society.

Stouffer realized that diversity may sometimes foster intolerance. For example, a high rate of social and geographic mobility within the society could serve to raise aspirations beyond the possibility of achievement for many. Psychological strain could result from feeling relatively deprived. In addition, rapid social change could produce value conflicts within the mind of the individual. In either case, relative deprivation or value conflict, persons might react by displacing their anxiety (scapegoating) and thus trying to prevent others from exercising their civil rights. Nevertheless, while aware of these possibilities, Stouffer (222) felt that "For the long run ... the mechanisms in American social change which are tending to facilitate tolerance are far more potent than the mechanisms which impede it."

\section{SAMPLING}

Stouffer's data were collected in the Spring of 1954 from two probability samples. The combined sample contains information from 4,933 adult respondents in the coterminous United States. The completion rate was 84 percent. Data for the replication were collected in the Spring of 1973 through a probability sample of the adult population in the coterminous United States. ${ }^{2}$ The completion rate was 70 percent yielding a total of 3,546 cases. The refusal rate was 17 percent with the other noncompletions stemming primarily from designated respondents not being home after four visits. No quota elements were present in either sample. 
The statistical procedure used for much of the analysis in the present study requires complete information on all of the variables in the equation. Thus, the findings presented below are based on 4,433 of the cases from Stouffer's sample and 3,310 cases from the replication. ${ }^{3}$

\section{MEASUREMENT}

The major dependent variable in the original study is a scale of "willingness to tolerate noconformists." The scale is designed to measure acceptance of behavior even when it is disapproved. Questions were asked about four types of nonconformists: a Communist, an atheist, a Socialist, and a man whose loyalty has been questioned before a Congressional committee, but who swears under oath he has never been a Communist. For each type of nonconformist, questions were asked about such things as whether he should be allowed to keep his job, be allowed to make a speech in the community, and whether one of his books should be removed from the public library. ${ }^{4}$

Using the H-technique (Stouffer et al.), a Guttman scale was constructed using 15 items. The scale has a range of 0 (least tolerant) to 5 (most tolerant) and coefficients of reproducibility of .90 and scalability of $.68 .{ }^{5}$ For strict comparability, tolerance in the 1973 replication was measured in the same way as in the original. Using identical items, the scale has a coefficient of reproducibility of .90 and a coefficient of scalability of $.66 .^{6}$

The first study included a large number of social, cultural, and psychological variables and many of these were found to be associated with tolerance. To examine Stouffer's propositions discussed above, however, only those variables believed to be indices of exposure to social and cultural diversity have been selected for analysis. These are education, city size, region, exposure to mass media news, gender, and occupation. ${ }^{7}$ To compare findings from the two studies, the variables have been categorized using the coding from the original study.

\section{METHOD}

Both sets of survey data, the 1954 and 1973 samples, were analyzed using multiple classification analysis (cf. Andrews et al.). This procedure provides a measure of association between each independent variable and the dependent variable after controlling for all of the other independent variables in the equation. Using additive multiple least-squares regression, the procedure adjusts the mean of the dependent variable for each category of the independent variables by the amount of deviation from the total sample (grand) mean that is due to intercorrelation with other independent variables in the analysis. ${ }^{8}$ 


\section{FINDINGS}

\section{EXPOSURE TO DIVERSITY AND TOLERANCE}

\section{Education}

Stouffer's major point about education is that young people are likely to be exposed to values different from those learned in the home. He suggests that a lessening of authoritarian rigidity in the classrooom has resulted in a system which challenges tradition and stimulates independence of thought. Recent research, within a comparative framework, does show that education in the United States emphasizes cognitive skills as opposed to rote learning (cf. Simpson). Herriott and Hodgkins report that American schools increased both in size and complexity between 1930 and 1970, and several studies have found that the political and social awareness derived through education promotes values consistent with a tolerant attitude (cf. Campbell et al.; McClosky; Nunn; Prothro and Grigg).

Table 1 shows the mean scores on the scale of willingness to tolerate nonconformists for each category of education for the 1954 and 1973 populations, both before and after controlling for the other variables in the analysis. As expected, the higher the level of education, the greater the likelihood of being tolerant. In fact, among all of the independent variables being considered, education is the most important in the development of tolerance. ${ }^{9}$

\section{City Size}

The urban environment may be the most widely cited determinant of exposure to contrasting social and cultural characteristics. Contemporary studies stressing this point include Inkeles, Lenski, and Milgram. However, at least one study (Fischer) reports that city size is not associated with tolerance.

The relationship between city size and tolerance for the present study can be seen in Table 2. From these findings it appears clear that people who live in metropolitan areas tend to be more tolerant than others. Farm residents in 1973 remained the least tolerant segment of the American population. There is no way to reconcile these findings with those reported by Fischer since he used different measures. However, the findings presented here are based on a scale measuring tolerance rather than a single item and are derived from national probability samples collected at two points in time.

\section{Region}

Stouffer's interpretation of regional differences in tolerance included the idea that some regions contain more inmigrants than others, the assumption being that exposure to diversity increased as a result of geographic mobility. He also noted that regions receiving the highest rates of migrants should provide the greatest heterogeneity among their populations. Thus, living in a particular region may expose an individual to more or less diversity even when that individual has never personally experienced mobility. 
Table 1. IN 1954 AND 1973 EDUCATION IS POSITIVELY ASSOCIATED WITH WILLINGNESS TO TOLERATE NONCONFORMISTS

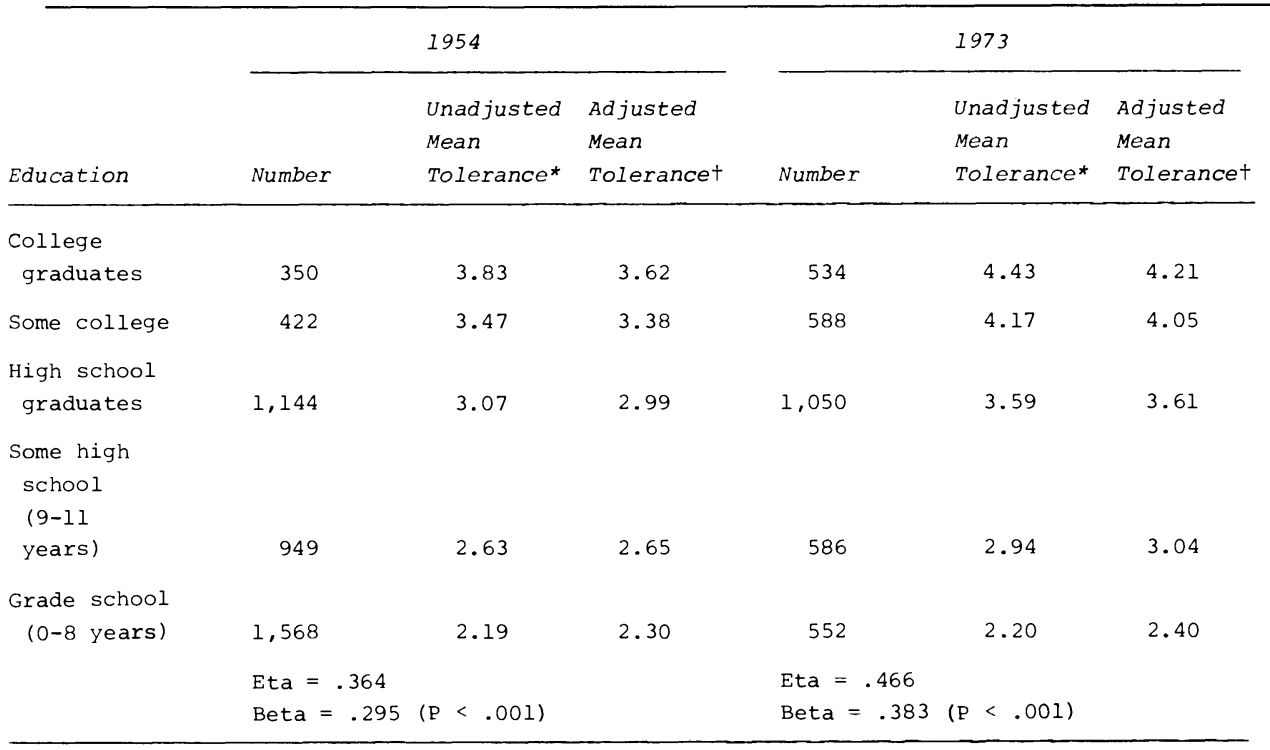

*The unadjusted means are mean tolerance scores before controlling for other

†The adjusted mean are mean tolerance scores after

to mass media news, gender, and occupation.

Table 2. IN 1954 AND 1973 CITY SIRE IS POSITIVELY ASSOCIATED WITH WILLINGNESS TO TOLERATE NONCONFORMISTS

\begin{tabular}{|c|c|c|c|c|c|c|}
\hline \multirow[b]{2}{*}{ City Size } & \multicolumn{3}{|c|}{1954} & \multicolumn{3}{|c|}{1973} \\
\hline & Number & $\begin{array}{l}\text { Unadjusted } \\
\text { Mean } \\
\text { Tolerance* }\end{array}$ & $\begin{array}{l}\text { Adjusted } \\
\text { Mean } \\
\text { Tolerancet }\end{array}$ & Number & $\begin{array}{l}\text { Unadjusted } \\
\text { Mean } \\
\text { Tolerance* }\end{array}$ & $\begin{array}{l}\text { Adjusted } \\
\text { Mean } \\
\text { Tolerancet }\end{array}$ \\
\hline \multicolumn{7}{|c|}{$\begin{array}{l}\text { Metropolitan } \\
\text { areas }(100,000 \\
\text { or more) }\end{array}$} \\
\hline \multicolumn{7}{|c|}{$\begin{array}{l}\text { Other cities } \\
(2,500 \text { up to }\end{array}$} \\
\hline 100,000$)$ & 1,229 & 2.73 & 2.69 & 1,001 & 3.31 & 3.39 \\
\hline \multicolumn{7}{|c|}{$\begin{array}{l}\text { Small towns } \\
\text { (under } 2,500 \\
\text { including } \\
\text { rural non- }\end{array}$} \\
\hline farm) & 804 & 2.60 & 2.64 & 672 & 3.01 & 3.25 \\
\hline \multirow[t]{2}{*}{ Farms } & 677 & 2.25 & 2.57 & 115 & 2.56 & 2.92 \\
\hline & $\begin{array}{l}\text { Eta }= \\
\text { Beta }=\end{array}$ & $(P<.001)$ & & $\begin{array}{l}\text { Eta }= \\
\text { Beta }=\end{array}$ & $(\mathrm{P}<.001)$ & \\
\hline
\end{tabular}

*The unadjusted means are mean tolerance scores before controlling for other variables.

tThe adjusted means are mean tolerance scores after controlling for education, region, exposure to mass media news, gender, and occupation. 
The rates of inmigration by region were not measured in the original study, but the West was reported to have the highest rate. Data from the U.S. Bureau of the Census (1953) were examined to verify this assumption. Although based on the total 1950 population, rather than the adult population, the findings showed that the West had by far the largest percentage of inmigrants while the other regions were not very different from each other. Analysis of regional differences in 1970 (Census Bureau, 1973) yielded a similar, but slightly attenuated pattern. Other studies using different indicators of regional heterogeneity have produced similar results. Schooler, for example, has used indicators of industrialization and concluded that the Mountain and Pacific states are the most complex. ${ }^{10}$

Table 3 shows the mean level of tolerance for each region. As can be seen, regional differences in tolerance persist. Westerners continue to be more tolerant than persons living in other regions while southerners remain the least tolerant. However, whereas the greatest difference in tolerance might be expected between the West and other regions, based on the inmigration data, the largest difference is between the South and other regions. Doubtlessly there are unmeasured variables affecting the tolerance scores, possibly additional differences among the regions.

Table 3. IN 1954 AND 1973 THE WEST HAS THE HIGHEST LEVEL OF WILLINGNESS TO TOLERATE NONCONFORMISTS FOLLOWED IN ORDER BY THE EAST, MIDWEST, AND SOUTH

\begin{tabular}{|c|c|c|c|c|c|c|}
\hline \multirow[b]{2}{*}{ Region } & \multicolumn{3}{|c|}{1954} & \multicolumn{3}{|c|}{1973} \\
\hline & Number & $\begin{array}{l}\text { Unadjusted } \\
\text { Mean } \\
\text { Tolerance* }\end{array}$ & $\begin{array}{l}\text { Adjusted } \\
\text { Mean } \\
\text { Tolerancet }\end{array}$ & Number & $\begin{array}{l}\text { Unadjusted } \\
\text { Mean } \\
\text { Tolerance* }\end{array}$ & $\begin{array}{l}\text { Adjusted } \\
\text { Mean } \\
\text { Tolerancet }\end{array}$ \\
\hline West & 585 & 3.29 & 3.11 & 576 & 4.04 & 3.81 \\
\hline East & 1,149 & 3.05 & 2.96 & 779 & 3.81 & 3.67 \\
\hline Midwest & 1,343 & 2.83 & 2.82 & 910 & 3.44 & 3.47 \\
\hline \multirow[t]{2}{*}{ South } & 1,356 & 2.23 & 2.39 & 1,045 & 2.96 & 3.16 \\
\hline & $\begin{array}{l}\text { Eta }= \\
\text { Beta }=\end{array}$ & $(\mathrm{P}<.001)$ & & $\begin{array}{l}\text { Eta }= \\
\text { Beta }=\end{array}$ & $(\mathrm{P}<.001)$ & \\
\hline
\end{tabular}

*The unadjusted means are mean tolerance scores before controlling for other variables.

tThe adjusted means are mean tolerance scores after controlling for education,

city size, exposure to mass media news, gender, and occupation.

\section{Exposure to Mass Media News}

Along with education and geographic mobility, Stouffer believed that the mass media would be a primary factor in bringing people into contact with ideas, values, and other social and cultural characteristics different from their own. Unfortunately, however, exposure to mass media in general was not measured in the original study. Respondents were asked how often they read a newspaper, but questions about 
exposure to television and radio were limited to news programs. Furthermore, even if these questions had been worded differently, comparison with the 1973 data would remain problematic. Only 60 percent of the respondents in the original study had television sets and the content of radio programing has changed greatly since 1954. The effects of newspaper reading can be measured, but this represents exposure to only one of the several media. Thus, for comparative purposes, a general measure of exposure to mass media independent of specific sources was needed. ${ }^{11}$ The following question, although limited to media news, comes closest to meeting this requirement:

Frequently there is something in the news about Communists in the United States and what is being done about them. On the whole, would you say you follow this news very closely, fairly closely, or hardly at all?

When the original study was conducted it would have been difficult to be exposed to mass media news without being exposed to news about Communists in the United States. This was not true in 1973. Hence, a different question, designed to measure the same underlying factor of exposure to mass media news, was asked in the second survey: ${ }^{12}$

Frequently there is something in the news on such topics as war protestors, campus unrest, women's liberation, and black militants. On the whole, would you say you follow this news very closely, fairly closely, or hardly at all?

Table 4 shows the association between exposure to mass media news and tolerance. Although in the expected direction, this variable does not make an independently significant contribution to the explained variance in tolerance (with alpha at .01). A comparison of the unadjusted with the adjusted means suggests that most of the difference can be accounted for by the other variables in the analysis. This does not indicate, of course, that exposure to mass media in general has no effect on attitudes, but it does imply that this variable may have less of an independent effect on tolerance than Stouffer had believed.

\section{Gender}

In the original study gender was perceived as an index of exposure to diversity under the assumption that women are more likely to be socially isolated than men. In a recent discussion of gender differences in political attitudes and behavior Orum et al. distinguish between those who have attributed this difference to political socialization in childhood and those who related the difference to situational factors as adults. Stouffer (153) anticipated both of these perspectives while pointing out that both emphasize the greater exposure of men to social and cultural diversity.

Table 5 shows the mean tolerance scores for men and women. Both in 1954 and 1973 gender is significantly associated with tolerance with men being more tolerant than women. We will return to this finding below. 
Table 4. IN 1954 AND 1973 EXPOSURE TO MASS MEDIA NEWS IS NOT ASSOCIATED WITH WILLINGNESS TO TOLERATE NONCONFORMISTS

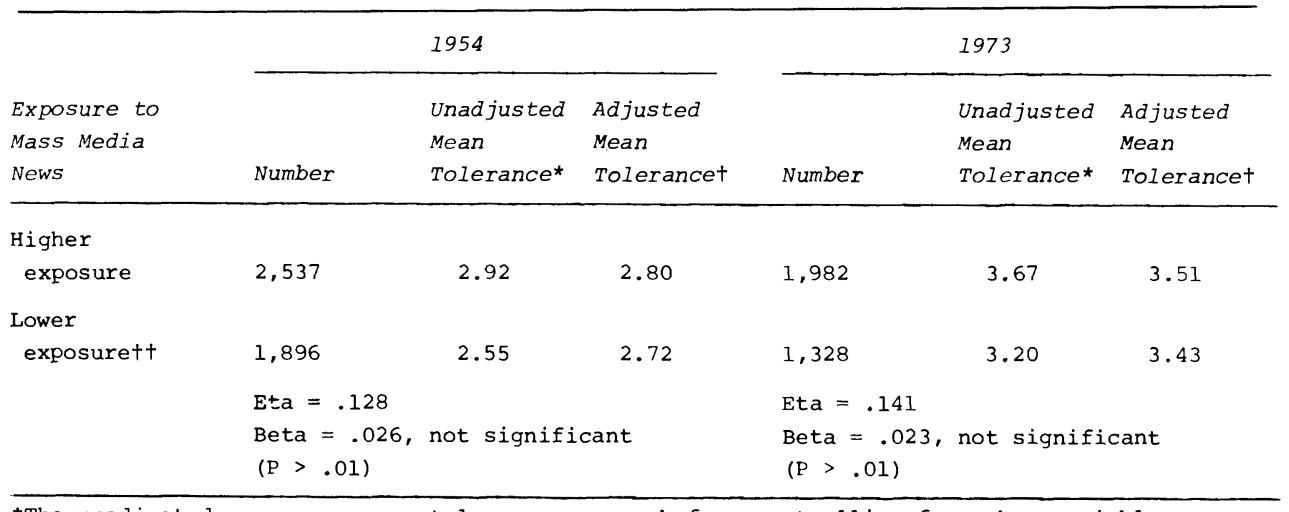

\footnotetext{
*The unadjusted means are mean tolerance scores before controlling for other variables

TThe adjusted means are mean tolerance scores after controlling for education, city size, region, génder, and occupation.

†Following Stouffer, higher exposure represents those who answered "very closely" and

"fairly closely."
}

\section{Occupation}

Data from Stouffer's study show that the higher the occupational status, the higher the percentage of tolerant people. Although he makes no mention of this in relation to diverse contacts, more recent research makes it clear that white-collar occupations are more likely to expose people to a variety of experiences than are blue-collar and farming occupations. Kohn, for example, points out that white-collar workers

Table 5. IN 1954 AND 1973 MALES ARE MORE WILLING TO TOLERATE NONCONFORMISTS THAN FEMALES

\begin{tabular}{|c|c|c|c|c|c|c|}
\hline \multirow{2}{*}{ Gender } & \multicolumn{3}{|c|}{1954} & \multicolumn{3}{|c|}{1973} \\
\hline & Number & $\begin{array}{l}\text { Unadjusted } \\
\text { Mean } \\
\text { Tolerance* }\end{array}$ & $\begin{array}{l}\text { Adjusted } \\
\text { Mean } \\
\text { Tolerancet }\end{array}$ & Number & $\begin{array}{l}\text { Unadjusted } \\
\text { Mean } \\
\text { Tolerance* }\end{array}$ & $\begin{array}{l}\text { Adjusted } \\
\text { Mean } \\
\text { Tolerance' }\end{array}$ \\
\hline Males & 1,985 & 2.93 & 2.95 & 1,451 & 3.79 & 3.73 \\
\hline Females & 2,443 & 2.63 & 2.61 & 1,859 & 3.24 & 3.29 \\
\hline & $\begin{array}{l}\text { Eta }= \\
\text { Beta }=\end{array}$ & $<.001)$ & & $\begin{array}{l}\text { Eta }= \\
\text { Beta }=\end{array}$ & $<.001)$ & \\
\hline
\end{tabular}

*The unadjusted means are mean tolerance scores before controlling for other variables.

tThe adjusted means are mean tolerance scores after controlling for exposure to mass media news, and occupation. 
generally deal with ideas and people, whereas blue-collar workers deal with tools, machines, and the like. The somewhat solitary nature of farming would appear to isolate farmers from diverse contacts at least as much as blue-collar workers. Stouffer believed that housewives are less likely to be exposed to alternative social and cultural forms than either blue- or white-collar workers.

The first analysis of the data showed persons in white-collar occupations having a higher adjusted mean tolerance score than those in the other two categories. Contrary to expectations, however, housewives were found to be as tolerant as bluecollar workers and farmers. This finding was especially confusing since women are significantly less tolerant than men. Consequently, an attempt was made to clarify these findings by examining the possible impact of occupational status on men and women separately.

As can be seen from Table 6, the findings for men in both samples support the hypothesis that white-collar persons are more tolerant than those in blue-collar and farming occupations. On the other hand, occupational status is not significantly associated with tolerance among women. However, it would be premature to conclude that this finding confirms the political socialization hypothesis discussed above. In the first place, research has yielded contradictory evidence about those aspects of socialization which might result in boys being exposed to a greater variety of experiences than girls (cf. Maccoby and Jacklin). Second, as Riesman suggested in reference to Stouffer's data, the jobs typically available to women may not provide the diverse experiences encountered by men. In fact, the sedentary and monotonous work of many "female jobs" may afford even less contact with different ideas and values than being a housewife.

\section{CHANGE IN THE LEVEL OF TOLERANCE}

Based on the social and demographic trends present in 1954, Stouffer hypothesized that the society would become more tolerant. That many of these trends have continued can be seen from the data presented above. The population has become far more educated; moving from a majority who never graduated from high school to a nation in which the high school graduate is commonplace and more than one of every three adults has attended college. Rural to urban migration has continued with a significant buildup in metropolitan areas and a sharp decline in farm residents. Due to a lack of relevant information in the 1954 study, possible change in regional complexity through inmigration cannot be measured by comparing the 1954 and 1973 surveys. U.S. Bureau of the Census (a, b) data, however, show the West having the largest proportion of inmigrants for both points in time. The proportion who say they follow the news closely has increased only slightly. Two major changes have occurred in the gender-occupation distribution: there has been an increase in the proportion of men and women in white-collar jobs and in the proportion of gainfully employed women. Among these variables, the only two not found to be significantly associated with tolerance are exposure to mass media news and the occupational status of women. Consequently, changes in the distributions of 
Table 6. IN 1954 AND 1973 OCCUPATION IS ASSOCIATED WITH WILLINGNESS TO TOLERATE NONCONFORMISTS AMONG MEN, BUT NOT AMONG WOMEN

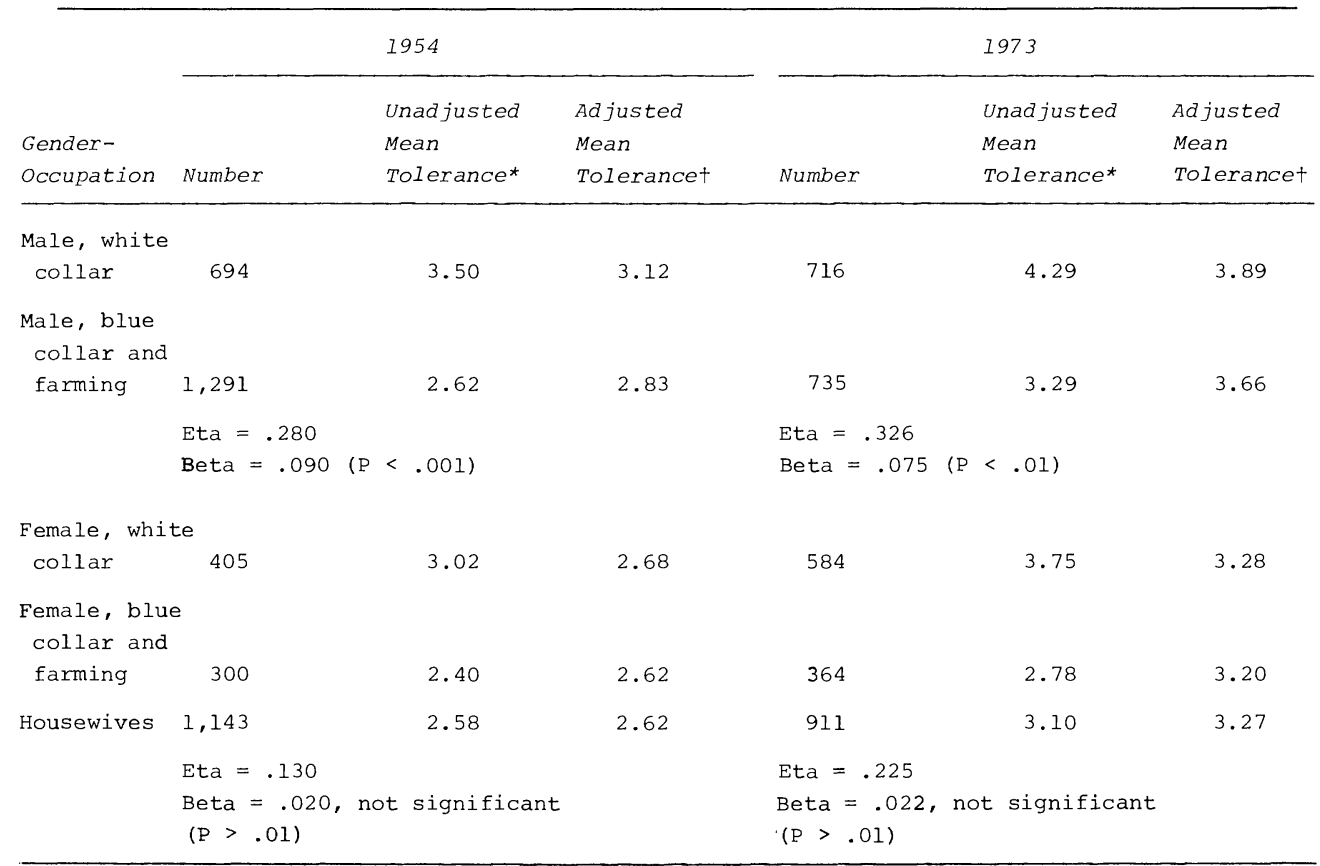

*The unadjusted means are mean tolerance scores before controlling for other variables.

tThe adjusted means are mean tolerance scores after controlling for education, city size, region, and exposure to mass media news.

these variables in the direction of exposing a larger proportion of the population to social and cultural diversity should have produced a more tolerant society. ${ }^{13}$

Table 7 shows the percentage change at each level of tolerance on the scale and the mean change between 1954 and 1973. The population has become more tolerant with the most striking change at the highest level on the scale.

The significant rise in the level of tolerance provides further support for Stouffer's propositions. However, it should be pointed out that the change cannot be attributed solely to the distributional changes in the independent variables considered in the analysis. This can be seen by comparing the 1954 and 1973 mean tolerance scores within categories of the independent variables (Tables 1 through 6). Tolerance has increased within every category. This is not inconsistent with the general theory, however. There probably are variables not included in the present analysis which also are operating to expose more people to diversity. Furthermore, as Stouffer suggested, the impact of the measured variables may have changed in a toleranceproducing direction. For example, education at every level, especially beyond grade school, may be providing a greater variety of stimuli than previously. 
Table 7. IN 1973 AMERICANS WERE MORE WILLING TO TOLERATE NONCONFORMISTS THAN IN 1954

\begin{tabular}{|c|c|c|c|c|}
\hline \multirow{2}{*}{$\begin{array}{l}\text { Willingness } \\
\text { to Tolerate } \\
\text { Nonconformists }\end{array}$} & \multicolumn{2}{|c|}{1954} & \multicolumn{2}{|c|}{1973} \\
\hline & Number & Percent & Number & Percent \\
\hline \multicolumn{5}{|l|}{ Less tolerant* } \\
\hline 0 & 298 & 7 & 171 & 5 \\
\hline 1 & 535 & 12 & 313 & 9 \\
\hline \multicolumn{5}{|l|}{ In-between } \\
\hline 2 & 1,236 & 28 & 495 & 15 \\
\hline 3 & 965 & 22 & 474 & 14 \\
\hline \multicolumn{5}{|l|}{ More tolerant } \\
\hline 4 & 649 & 15 & 489 & 15 \\
\hline 5 & 751 & 17 & 1,368 & 41 \\
\hline $\begin{array}{l}\text { 1954, mean } t \\
1973, \text { mean } t \\
\text { Difference i }\end{array}$ & $\begin{array}{l}\text { lerance }= \\
\text { lerance } \\
\text { means }=\end{array}$ & $\begin{array}{l}2.76 \\
3.48 \\
0.72 \quad(P<.\end{array}$ & using & T-test) \\
\hline
\end{tabular}

\section{SUMMARY AND CONCLUSIONS}

On the basis of his national study, Stouffer proposed that contact with social and cultural diversity is an important determinant of tolerance. As a first step, contact allows people to discover that persons with different attributes or cultural orientations are not always dangerous. Once having learned this lesson, people become more receptive to the fact that the protection of civil rights, even when the protected behavior seems harmful, is necessary for assuring their own freedom. Finally, individuals will recognize that honoring civil liberties is not only valuable for selfprotection, but is vital to the preservation of a democratic society.

A 1973 replication of Stouffer's study found that his scale of willingness to tolerate nonconformists continued to meet the reproducibility and scalability requirements for a Guttman scale. Moreover, additional analysis suggested that the attitudes measured by the scale may be generalized to nonconformity in general rather than being restricted to the specific types mentioned in the scale items. Using this scale as a measure of tolerance, Stouffer's proposition that exposure to social and cultural diversity is an important determinant of tolerance was examined through 6 indices: education, city size, region, exposure to mass media news, gender, and occupation. The 1954 data were reanalyzed, using a more rigorous statistical procedure than was used in the original study, and the 1973 data were analyzed 
using the same procedure and variables. With the exceptions of exposure to mass media news and female employment, all of Stouffer's propositions were supported.

Given a continuation of social and demographic trends present in 1954, an increase in the proportion of the population exposed to diversity would be expected. And, as a result, the society should have become more tolerant. Comparisons of the surveys show that these trends have continued and that the population has become more tolerant. Although the change in tolerance cannot be attributed solely to these trends, they would appear to have played an important part in fostering a marked increase in tolerance. Only 17 percent of the 1954 population fell into Stouffer's most tolerant category. By 1973, 41 percent of adult Americans had moved into this category.

The research for Communism, Conformity, and Civil Liberties was done during a period in American history when it appeared that many might be willing to sacrifice civil liberties in the interest of national security. From May through July 1954, the months during which the data were collected for the study, no less than 54 issues of the New York Times gave front-page coverage to the ArmyMcCarthy hearings. That civil liberties were under attack needs little documentation. The 19 years which passed before the second study scarcely saw a let up in threats to liberty. By 1973 the public had heard appeals to deny civil rights to persons engaged in a variety of activities including such diverse behaviors as growing long hair, topless dancing, teaching about sex in the public schools, and protesting against government policies. The army was reported to have been secretly collecting files on private citizens and the Watergate affair was making headlines. Despite these events, and many others like them, the "great social, economic, and technological forces", which Stouffer called attention to appear to have continued to work on the side of producing an ever more tolerant society. As people have encountered diversity, in the classroom, the city, on the job, in moving from one region to another, in meeting people from other sections of the nation, they have become more willing to respect the civil liberties of others, even when their ideas challenge long-standing traditions and cherished values. Barring a major crisis or a cessation or reversal of current trends, tolerance should continue to increase in the future.

\section{NOTES}

1. This portion of Stouffer's theory has been examined by several studies testing what has been referred to as the "contact hypothesis." Although important in their own right, these studies do not provide a test of his more general set of propositions, however. They typically have been confined to the narrower limits of intergroup contact and the dependent variable is usually a measure of positive or negative sentiment toward members of the other group. Stouffer's definition of tolerance includes the notion of respecting another's rights even when disapproving of the other's behavior or disliking him or her for whatever reason.

2. Most of the interviews, 98 percent, were conducted in March, April, and May 1973. The other 2 percent were completed in June. Analysis of the data by date of interview shows no significant changes in tolerance during this time. Hence, events occurring during the interview period, such as Watergate revelations, had no detectable effect on the results.

3. Two potential problems arose in sample comparability. First, the 1973 survey includes persons age eighteen through twenty, whereas the 1954 survey defined adults as persons age twenty-one or above. Second, because of the desirability of including occupation as an independent variable, respondents classified as retired or unemployed had to be deleted from the 1954 sample. Persons having these statuses 
in the 1973 survey were retained by assigning them their last or previous occupation, information not obtained in the original study. After deciding it would be preferable to present findings from the 1973 study using the most complete sample possible, it was necessary to ascertain whether the differences between the two samples could lead to erroneous interpretations when comparing results. To this end, the 1973 data were reanalyzed, after deleting persons under age twenty-one and the retired and unemployed. The findings are essentially the same and do not alter the conclusions in this paper.

4. A complete listing of the items and scale-construction procedures appears in Stouffer (262-6).

5. Stouffer reports a coefficient of reproducibility of .96. Using several alternative methods, the investigators were unable to replicate this figure. Apparently, a computation error was made in the original analysis.

6. Stouffer was reluctant to generalize beyond attitudes toward the kinds of nonconformists mentioned in the items making up the scale. Thus, even though the scale meets the appropriate statistical criteria of reproducibility and scalability, a question about its generalizability remains. The investigators attempted to answer this question by examining the relationship between the scale and measured tolerance toward 7 types of nonconformist, but legal, activities which are not mentioned in the items making up the scale. For 5 of these (the first 5 listed below), respondents were first asked if they approved and then whether the activity should be allowed. Approval of an activity precludes measuring that part of tolerance which says a person will grant rights to people whose behavior he or she disappoves. However, at least it is known that these people are willing to extend rights to those engaging in these activities. Approval ranged from a high of 83 percent in favor of black and white children going to the same school to only 27 percent approving the showing of X-rated movies. If a respondent did not approve, but then said the behavior should be allowed, he or she is unambiguously expressing a tolerant attitude. Those who disapproved, but who qualified their opinion about allowing the activity (by saying “'it depends') may be considered somewhat less tolerant and those who disapproved and said they would not allow the behavior are the least tolerant. For the other two items, responses of disagree and strongly disagree were classified as tolerant with the latter being the most tolerant. The willingness-to-tolerate-nonconformists scale was found to be significantly associated with each of the 7 items $(\mathrm{P}<.001)$, both before and after controlling for the other 6 items in the analysis. The items and their degree of association with the scale are as follows:

\section{Product-moment Regression Correlation Coefficient}

A woman running for president .35 .14 of the U.S.

Black and white children going to the same school

Demonstrating against a war like the one in Vietnam

Showing X-rated movies more like other children

A child should never be allowed

to talk back to his parents

In addition to the items listed above, respondents were asked if they approved of teaching about Communism in the schools and then whether this should be allowed. Using the scaling procedure discussed above, this item has a correlation of .39 with the scale of willingness to tolerate nonconformists. Hence, an item explicitly related to Communism is no more highly correlated with Stouffer's scale than are items not related to Communism.

As a final test of the generalizability of the tolerance scale it was included along with the 7 items in a factor analysis. Only 1 factor emerged using Guttman's criterion. Since the one thing which each of these items, including Stouffer's scale, has in common is a willingness to extend civil liberties to nonconformists, it seems reasonable to assert that the underlying factor is a measure of tolerance and that the scale of willingness to tolerate nonconformists may be generalized to nonconformists not specifically mentioned in the items which compose it. 
A detailed discussion of the procedures used to examine the generalizability of Stouffer's scale will be presented in a forthcoming monograph.

7. An analysis which included age, religion, and ethnicity did not alter the conclusions reached about the effects of the variables on tolerance included in this paper.

8. The analysis assumes an additive model and tests of significance are based upon this assumption. A separate analysis was made including all first-order interactions among the independent variables. Including the interactions does not add a statistically significant increment to explained variance in the 1954 sample, but it does $(\mathrm{P}<.001)$ in the 1973 sample. Substantively, however, the increase in explained variance is small $(1.5 \%)$ and including the interaction variables does not alter the conclusions reached by using the more easily interpretable model.

9. Jackman has suggested that education, rather than fostering tolerance, may simply reflect the ability of the better educated to provide a socially approved response. While there may be an element of fact in the ability of the educationally sophisticated person to anticipate a culturally prescribed response, there is considerable evidence contradicting this interpretation as the major explanation of the education-tolerance relationship. However, an adequate discussion of this point is beyond the scope of this paper. The authors are presently completing another paper which deals with this point in detail.

10. Data from the 1973 survey also were examined with regard to regional mobility both for respondents and parents of respondents. Consistent with the Census, the East, Midwest, and South have about the same percentages of respondents born outside the region, but the East contains larger percentages of respondents having a parent born elsewhere. The South contains the smallest percentages of both. Consequently, given that there are cultural differences among regions, and there is evidence to this effect (cf. Glenn and Simmons), the highest level of tolerance should be found in the West followed, respectively, by the East, Midwest, and South.

11. Another approach would be to scale exposure to several media. To see if this would yield any difference in the findings a scale was constructed from questions about newspaper reading and listening to news on radio and television. The results are almost identical to those given in this paper.

12. A scale was constructed from questions about newspaper reading, listening to television news, and reading magazines. Using this scale in place of the other measure produced the same results.

13. Other studies have shown increased tolerance over shorter periods of time (cf. Jennings and Niemi) and two recent papers have found increased tolerance using some of Stouffer's scale items (Cutler and Kaufman; Davis). But the findings presented here have the advantage of being based on the complete scale of willingness to tolerate nonconformists given at two points in time 19 years apart.

\section{REFERENCES}

Andrews, Frank, James Morgan, John Sonquist, and Laura Klein. 1973. Multiple Classification Analysis. Ann Arbor: Institute for Social Research, University of Michigan.

Bureau of the Census. a:1953. U.S. Census of Population: 1950. Vol. 4, Special Reports, Part 4, "State of Birth." Washington: Government Printing Office.

b:1973. U.S. Census of Population: 1970. Final Report PC(2)-2D, "Lifetime and Recent Migration."' Washington: Government Printing Office.

Campbell, Vincent N., Manford J. Ferris, and Daryl G. Nichols. 1971. National Assessment Report 6: Citizenship. Washington: Government Printing Office.

Cutler, S. J., and R. L. Kaufman. 1973. "Cohort Changes in Political Attitudes: An Analysis of Tolerance of Ideological Nonconformity.' Paper presented at the annual meeting of the Gerontological Society.

Davis, J. A. 1974. “Tolerance of Atheists and Communists in 1954 and 1972-73." Paper presented at the annual meeting of the American Association of Public Opinion Researchers.

Durkheim, Emile. 1893. In George Simpson (trans.), The Division of Labor in Society. Glencoe: Free Press, 1933.

Fischer, C. S. 1971. "A Research Note on Urbanism and Tolerance.' American Journal of Sociology 76(March):847-55.

Glenn, N. D., and J. L. Simmons. 1967. “'Are Regional Cultural Differences Diminishing?” Public Opinion Quarterly 31(Summer):176-93. 
Herriott, Robert E., and Benjamin J. Hodgkins. 1973. Schooling: Formal Education As An Open Social System. Englewood Cliffs: Prentice-Hall.

Inkeles, A. 1966. "The Modernization of Man." In Myron Weiner (ed.), Modernization. New York: Basic Books.

Jackman, R. W. 1972. "Political Elites, Mass Publics, and Support for Democratic Principles.' Journal of Politics 34(August):753-73.

Jennings, M. K., and R. G. Niemi. 1973. "Continuity and Change in Political Orientations: A Longitudinal Study of Two Generations." Paper presented at the annual meeting of the American Political Science Association.

Kohn, Melvin L. 1969. Class and Conformity. Homewood: Dorsey.

Lenski, Gerhard E. 1961. The Religious Factor. New York: Doubleday.

Maccoby, Eleanor S., and Carol N. Jacklin. 1974. The Psychology of Sex Differences. Stanford: Stanford University Press.

McClosky, H. 1964. "Consensus and Ideology in American Politics." American Political Science Review 58(June):361-82.

Milgram, S. 1970. “'The Experience of Living in Cities.' Science 167(March)1461-68.

Nunn, C. Z. 1973. "'Support of Civil Liberties Among College Students.' Social Problems 20(Winter):300-10.

Orum, A. M., R. S. Cohen, S. Grasmuck, and A. Orum. 1974. "Sex, Socialization and Politics." American Sociological Review 39(April):197-209.

Prothro, J. W., and C. M. Grigg. 1960. "Fundamental Principles of Democracy: Bases of Agreement and Disagreement." Journal of Politics 22(May):276-94.

Riesman, D. 1956. "Orbits of Tolerance, Interviewers, and Elites." Public Opinion Quarterly 20(Spring):49-73.

Schooler, C. 1972. "'Social Antecedents of Adult Psychological Functioning." American Journal of Sociology 78(September):299-322.

Simmel, G. 1903. "'The Metropolis and Mental Life." In Kurt H. Wolff (ed.), The Sociology of Georg Simmel. New York: Free Press, 1950.

Simpson, M. 1972. "Authoritarianism and Education: A Comparative Approach." Sociometry 35(June):223-34.

Stouffer, Samuel A. 1955. Communism, Conformity and Civil Liberties. New York: Doubleday.

Stouffer, S. A., E. F. Borgatta, D. G. Hays, and A. F. Henry. 1952. "A Technique for Improving Cumulative Scale.” Public Opinion Quarterly 16(Summer):273-91.

Wirth, L. 1938. "Urbanism as a Way of Life." American Journal of Sociology 44(July):3-24. 